\section{Perkerasan Kaku (Rigid Pavement) Pada Ruas Jalan Posing Kabupaten Murung}

\section{Raya}

\begin{tabular}{|l|}
\hline Pas foto \\
$2 \times 3$ \\
\hline
\end{tabular}

\section{BOBIE, ST}

Lahir di Tewang Baringin tanggall 29 Juli 1981 anak pertama dari tiga bersaudara, buah dari pasangan Kuar Alai dan Lisne. tahun 1987 umur 6 tahun masuk SDN-1 Tewang Baringin, setelah lulus tahun 1993 melanjutkan masuk SMPN-3 Tewang Sanggalang Garing, lulus Tahun 1996 melanjutkan Pendidikan di STM Palangka Raya, lulus tahun 1998 masuk lembaga pendidikan Komputer dan Tahun 2000 Masuk Perguruan Tinggi. buletinppi@ulm.ac.id
Jalan Posing merupakan jalan baru hanya dilapisi Lapisan Pondasi Bawah (sub base course) dan subgrade yang berpori rentan tergenang air hujan sehingga beban kendaraan berat yang sering melewati jalan Posing mengakibatkan terciptanya kubangan lumpur kerusakan parah dan sampai terputusnya akses lalu lintas. Kasus tersebut mendorong Pemerintah Daerah untuk segera mengalokasikan anggaran pembiayaan Proyek "Peningkatan Jalan Posing" melalui perencanaan yang dilakukan berusaha untuk mengatasi dampak kerusakan yang terjadi pada jalan tersebut, yaitu dengan Perencanaan Jalan Beton (Rigid pavement). Dari hitungan yang telah dilakukan diperoleh lapisan perkerasan beton dengan tebal $250 \mathrm{~mm}$ dan penulangan tepi arah melintang sebesar D $8-100 \mathrm{~mm}$ serta penulangan untuk arah memanjang diperoleh sebesar $D$ 8-100 mm.

Kata kunci : Kerusakan Jalan, Jalan Beton (Rigid Pavement), Penulangan Tepi, Sambungan Memanjang.

www.buletinppi.ulm.ac.id

\section{Pendahuluan}

Konstruksi perkerasan kaku (Rigid Pavement) banyak digunakan pada beban kendaraan yang relatif besar dan kondisi daya dukung tanah dasar (sub grade) yang rendah dan berpori menjadi alasan utama pemilihan jalan beton. Terlebih lagi strukturnya yang lebih kuat, awet, dan bebas perawatan.

Kelebihan dari konstruksi perkerasan kaku adalah sifat kekakuannya yang mampu menahan beban roda kendaraan dan menyebarkannya ke tanah dasar secara efisien. Jalan beton menjadi solusi yang sangat efektif untuk mengatasi kerusakan-kerusakan yang terjadi pada Ruas Jalan Posing. Oleh karena itu, perlu perencanaan untuk mengetahui karakteristik jalan beton, material apa saja yang digunakan, metode sambungan, penulangan, dan aplikasi perencanaan jalan beton di ruas Jalan Posing.

\section{Umum}

Pada dasarnya jalan beton direncanakan untuk menopang beban kendaraan lalu lintas yang relatif berat. Dalam perencanaannya, pelaksanaan jalan beton mengacu pada Petunjuk Perencanaan Jalan Beton Semen yang diterbitkan oleh Departemen Permukiman dan Prasarana Wilayah, SNI Pd T-14-2003.

Perencana dan pelaksana harus

sekitar lokasi proyek, sehingga tidak mengganggu atau merusak lingkungan sekitar.

\section{Tipe Konstruksi Jalan}

Perkerasan jalan dikenal dua macam tipe konstruksi yaitu :

1. Jalan aspal (fleksibel pavement)

2. Jalan beton (rigid pavement)

Perbedaan utama antara jalan beton dengan jalan aspal adalah terletak pada lapisan perkerasan di atasnya, jenis material yang digunakan, dan metode pengerjaan.

Di sini yang kita pergunakan untuk perkerasan Peningkatan Jalan Posing Kabupaten Murung Raya yaitu Jalan Beton (Rigid Pavement) dengan metode pelaksanaan menggunakan Beton bertulang dan sambungan (JRC, jointed reinforced concrete) perkerasan jalan beton dilaksanakan dalam beberapa tahap, mulai dari pekerjaan tanah (urugan dan galian), pembuatan lapis pondasi, dan lapisan di atasnya (berupa beton).

Susunan lapisan perkerasan jalan beton tersebut terdiri dari dua lapis, yaitu lapisan beton dan lapisan pondasi di bawahnya. Lapisan perkerasan beton dikerjakan secara per segmen dan diberi sekat untuk mengantisipasi resiko kerusakan akibat factor kembang susut (shrinkage). Lapis beton tersebut berada di atas mempertimbangkan berbagai faktor lingkungan $d i$ 
lapisan pondasi yang bisa berupa material berbutir dengan tebal $15 \mathrm{~cm}$.

Material timbunan pilihan untuk pondasi bawah dikerjakan sebelum pengecoran beton fungsinya sebagai timbunan/urugan yang digunakan untuk pencapaian elevasi akhir lapis pondasi bawah (subbase course) yang disyaratkan. Timbunan yang diklasifikasikan sebagai timbunan pilihan harus terdiri dari bahan tanah berpasir (sandy clay) atau padas yang memenuhi persyaratan dan sebagai tambahan harus memiliki sifat tertentu tergantung dari maksud penggunaannya. Dalam segala hal, seluruh urugan pilihan harus memiliki CBR paling sedikit $10 \%$, bila diuji sesuai dengan AASHTO T 193.

Jalan beton dari sisi perilaku strukturnya memang terlihat lebih baik, tegangan yang timbul akibat beban yang sama relatif lebih kecil, sehingga tidak diperlukan lapisan bawah (base- course) yang tebal. Namun karena materialnya dari beton, maka pengaruh kembang susut (shrinkage) akibat perubahan suhu menjadi dominan. untuk pelaksanaan Peningkatan Jalan Posing menggunakan Beton bertulang dan sambungan (JRC, jointed reinforced concrete) atau Konstruksi Jalan Beton dengan Sambungan Dowel. ditunjukkan pada Gambar berikut :

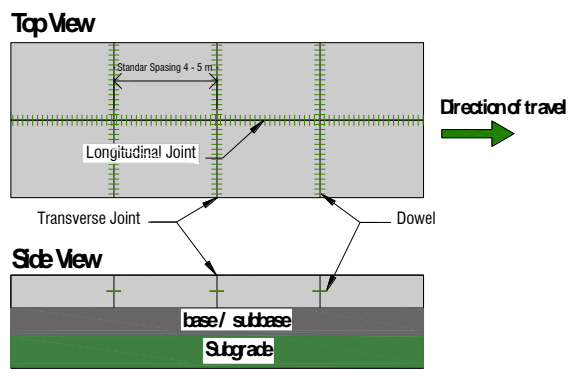

Gambar 1. Detail Konstruksi Jalan Beton dengan Sambungan Dowel

Sumber : Pavement Design Guide (1992)

Sambungan dowel berfungsi sebagai pengikat atau penyatu antar segmen. Siar dilatasi berfungsi untuk memberikan celah atau ruang untuk pemuaian, dan pemasangan tulangan susut berfungsi untuk mengatasi pengaruh kembang susut beton (shrinkage).

\section{Menentukan Tebal Pelat Beton}

Tebal pelat beton dihitung agar mampu memikul tegangan yang ditimbulkan oleh :

a. Beban roda kendaraan.

b. Perubahan suhu dan kadar air.

c. Perubahan volume pada lapisan di bawahnya.

Sesuai dengan metode pelaksanaan yang diterapkan untuk menentukan ketebalan pelat beton yaitu metode Beton bertulang dan sambungan (JRC, jointed reinforced concrete) maka ketebalan pelat beton yang diizinkan berkisar antara $200 \mathrm{~mm}-300 \mathrm{~mm}$, sedangkan untuk pelaksanaan perkerasan Jalan Posing Kabupaten Murung Raya diambil ketebalan 250 mm.

Untuk perhitungan secara konservatif, diterapkan prinsip kelelahan (fatigue) dimana dianggap apabila perbandingan tegangan yang terjadi pada beton akibat beban roda terhadap kuat lentur beton (Modulus of Rapture, MR) menurun, maka jumlah repetisi pembebanan sampai runtuh (failure) akan meningkat. Apabila perbandingan tegangan tersebut sangat rendah, maka beton akan mampu memikul repetisi tegangan yang tidak terbatas tanpa kehilangan kekuatannya.

\section{Penulangan Jalan Beton}

Besi tulangan yang dipakai dalam perkerasan kaku mempunyai fungsi utama untuk :

a. Membatasi lebar retakan, agar kekuatan pelat tetap dapat dipertahankan.

b. Memungkinkan penggunaan pelat yang lebih panjang agar dapat mengurangi jumlah sambungan melintang sehingga dapat meningkatkan kenyamanan.

c. Mengurangi pengaruh kembang susut karena perubahan suhu.

d. Mengurangi biaya pemeliharaan.

Besi tulangan yang dipakai harus bersih dari oli, kotoran, karat, dan pengelupasan. Tulangan harus dipasang sebelum pembetonan dengan diberi penyangga yang ditahan pada letak yang diinginkan. Ukuran atau jarak tulangan dari permukaan beton $60 \pm$ $10 \mathrm{~mm}$ di bawah permukaan beton, untuk tebal pelat kurang dari $270 \mathrm{~mm}$.

Jenis besi yang dipakai untuk pekerjaan Peningkatan Jalan Posing disini yaitu :

1. Tulangan tepi menggunakan besi U $24 \phi 8 \mathrm{~mm}$.

Tulangan baja untuk tepi tulangan pokok dan tulangan sengkang dianyam sesuai gambar dan harus memenuhi persyaratan- persyaratan AASHTO M 55.

2. Tulangan tie bar menggunakan besi U $32 \phi 12 \mathrm{~mm}$. Batang pengikat (Tie Bar) harus berupa batangbatang baja berulir sesuai dengan AASHTO M 31 .

3. Tulangan dowel menggunakan besi U $24 \phi 22 \mathrm{~mm}$. Batang baja untuk Dowel harus berupa batang bulat biasa sesuai dengan AASHTO M 31. Batang-batang Dowel berlapis plastic yang memenuhi AASHTO M 254.

Tulangan tepi pinggiran kiri dan kanan dibuat sengkang dengan ukuran lebar $20 \mathrm{~cm}$, tinggi $10 \mathrm{~cm}$ jarak antara sengkang $50 \mathrm{~cm}$, jumlah tulangan pokok sebanyak 5 batang. Tulangan tie bar dibuat jarak 30 $\mathrm{cm}$, dan besi dowel dengan jarak $30 \mathrm{~cm}$, sedangkan untuk tulangan tengah dan batas segmen dengan sengkang lebar $10 \mathrm{~cm}$ tinggi $10 \mathrm{~cm}$ dengan jarak antara sengkang $30 \mathrm{~cm}$. System penulangan pada perkerasan 
Jalan Beton pada Ruas Jalan Posing diperlihatkan pada Gambar berikut :

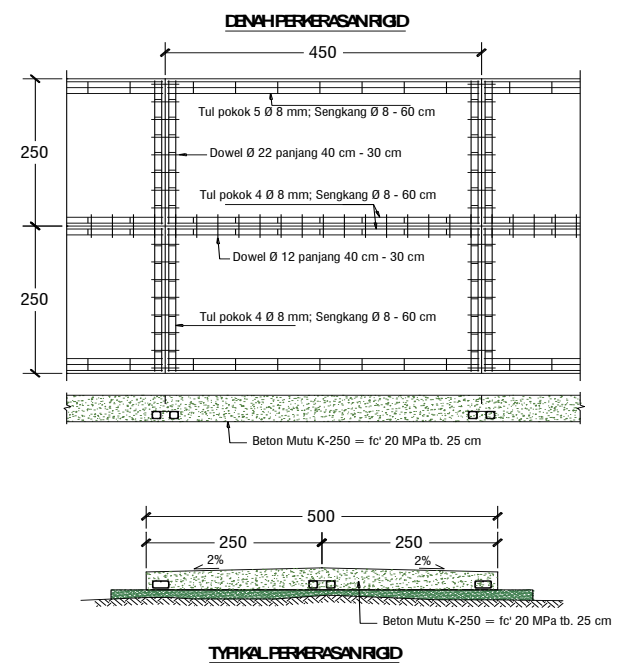

Gambar2. Detail Penulangan Perkerasan Rigid

Sumber : Perencanaan Peningkatan Jalan Posing

\section{Material Untuk Perkerasan Kaku}

\section{a. Beton}

Beton adalah campuran dari bahan agregat, semen dan air dengan komposisi tertentu. Beton yang digunakan untuk lapisan pada perkerasan kaku dihamparkan di atas lapisan pondasi atas yang biasanya tersusun dari batuan. Prosesnya, semen membentuk ikatan di dalam campuran, kemudian air yang ditambahkan membantu proses reaksi kimia yang mengubah semen yang kering menjadi perekat. Bila air terlalu sedikit, maka reaksinya menjadi tidak sempurna dan air yang terlalu banyak juga akan mengurangi kualitas atau mutu beton yang dihasilkan.

Campuran antara material juga sangat penting. Idealnya, setiap partikel agregat diselimuti oleh semen terlebih dahulu sebelum ditambahkan air. Kekuatan campuran yang tepat dari beton terutama disebabkan oleh agregat kasar. Bagian agregat halus harus diberikan secara tepat dan cukup untuk mengisi rongga atau celah antar agregat kasar yang ukurannya relatif besar. Jadi dapat disimpulkan bahwa mutu atau kualitas beton tergantung pada :

- Komposisi jumlah semen, agregat halus, dan agregat kasar di dalam campuran.

- Efisiensi campuran.

- Kekuatan tumbukan dari agregat kasar (mutu agregat).

- Kebersihan agregat dari lumpur dan zat- zat kimia lainnya.

- Jenis semen yang digunakan.

- Jumlah air yang digunakan (umumnya dengan ukuran rasio air/ semen).

- Tingkat pemadatan.

- Efisiensi pengeringan beton (curing).

Campuran beton didasarkan pada kekuatan rata-rata benda uji kubus beton. Jika syarat kekuatan sudah ditentukan, maka campuran harus didesain untuk memenuhi syarat tersebut.

Campuran beton umumnya ditentukan berdasarkan berat berbagai macam material yang digunakan. Perbedaan campuran ditentukan berdasarkan tingkat (grade) yang menggambarkan kekuatan minimum beton. Contohnya campuran beton grade 30 mempunyai kekuatan tekan pada usia 28 hari sebesar $30 \mathrm{~N} / \mathrm{mm} 2$.

Dalam proyek Peningkatan Jalan Posing, beton diaduk di Quary tempat pencampuran dalam mixer truck dan kontraktor sangat bertanggung jawab terhadap kualitas/mutu beton yang akan dicor. Perbandingan tingkat kekuatan beton untuk perkerasan dapat dilihat pada Tabel berikut.

Tabel 1. Lapis Permukaan dan Kualitas (Grade) Beton

\begin{tabular}{|c|c|c|}
\hline \multicolumn{2}{|c|}{ Pavement layer } & $\begin{array}{l}\text { Designed } \\
\text { mix grade }\end{array}$ \\
\hline \multirow{4}{*}{1} & Surface slabs: & C40 \\
\hline & Unreinforced concrete (URC) & \\
\hline & Jointed reinforced concrete (JRC) & \\
\hline & $\begin{array}{l}\text { Continuously reinforced concrete pavement } \\
\text { (CRCP) }\end{array}$ & $\mathrm{C} 40$ \\
\hline 2 & Continuously reinforced concrete roadbase & $\mathrm{C} 30$ \\
\hline 3 & $(\mathrm{CRCR})$ & $\mathrm{C} 20$ \\
\hline 4 & CRCP ground beam anchorages & C15 \\
\hline 5 & Wet lean concrete 4 ) for roadbases & C10 \\
\hline 6 & Wet lean concrete 3) for sub-bases & $\mathrm{C} 7,5$ \\
\hline 7 & Wet lean concrete 2 ) as required in & \\
\hline 8 & Wet lean concrete 1) appendix $7 / 1$ & \\
\hline 9 & Cement bound material category 1 (СBM1) & \\
\hline 10 & Cement bound material category 2 (CBM2) & For road bases \\
\hline \multirow[t]{2}{*}{11} & Cement bound material category 3 (СВМ3) & And sub-bases \\
\hline & Cement bound material category 4 (СВM4) & \\
\hline
\end{tabular}

Sumber :Roadwork Theory and Practice (1990)

\section{AGREGAT}

Agregat yang digunakan sangat bervariasi dalam suatu campuran beton. Kebersihan agregat juga menjadi faktor yang sangat penting. Agregat yang dipakai umumnya dibagi menjadi dua bagian, yaitu :

a. Agregat kasar : batu pecah. (material setempat)

b. Agregat halus : pasir. (material setempat)

Campuran beton berdasarkan jumlah material yang diperlukan untuk memproduksi $1 \mathrm{~m}^{3}$ beton $\mathrm{fc}^{\prime} 20 \mathrm{MPa}$ pada proyek Peningkatan Jalan Posing Kabupaten Murung Raya ditunjukkan pada Tabel 2 berikut.

Tabel 2. Pengujian Campuran Beton $\mathrm{K}-250=\mathrm{fc}^{\prime} 20$ $\mathrm{MPa}$

\begin{tabular}{|c|c|c|c|}
\hline URAIAN & $\begin{array}{c}\text { METODE } \\
\text { PENGUJIAN }\end{array}$ & $\begin{array}{l}\text { HASIL } \\
\text { TEST }\end{array}$ & SPESIFIKASI \\
\hline \multicolumn{4}{|l|}{ PASIR } \\
\hline Daerah Gradasi & & II & Zona I, II, III, \\
\hline Berat Jenis (SSD) & SNI 1970-2008 & 2.630 & \\
\hline Penyerapan & SNI 1970-2008 & $0.594 \%$ & \\
\hline Kadar Air & SNI 1971-2011 & $5.524 \%$ & \\
\hline \multicolumn{4}{|l|}{ BATU PECAH } \\
\hline Ukuran Maksimal & & & $40 \mathrm{~mm}$ \\
\hline Berat Jenis (SSD) & SNI 1969-2008 & 2.762 & \\
\hline Penyerapan & SNI 1969-2008 & $0.890 \%$ & \\
\hline Kadar Air & SNI 1971-2011 & $1.350 \%$ & \\
\hline
\end{tabular}




\begin{tabular}{|c|c|c|c|}
\hline Nilai Abrasi & SNI 2417-2008 & $28.09 \%$ & Maks. 40 \\
\hline \multicolumn{4}{|c|}{ PROPORSI CAMPURAN /M³ DALAM SATUAN BERAT } \\
\hline Aggregat Halus (pasir) & & $699.13 \mathrm{Kg}$. & \\
\hline \multicolumn{4}{|l|}{ Aggregat Kasar (Batu } \\
\hline Pecah) & & $1.139 .70 \mathrm{Kg}$. & \\
\hline Semen & & $394.23 \mathrm{Kg}$. & \\
\hline Air & & 166.93 Ltr & \\
\hline \multicolumn{4}{|c|}{ NILAI KUAT TEKAN BETON RATA-RATA } \\
\hline Benda Uji Bentuk & & & \\
\hline $\begin{array}{l}\text { Silinder Beton Umur } \\
7 \text { Hari }\end{array}$ & SNI 1974-2011 & 14.17 MPa & \\
\hline SLUMP & SNI 1972-2008 & $7 \mathrm{~cm}$ & $60-100 \mathrm{~mm}$ \\
\hline
\end{tabular}

Sumber : UPTD Balai Pengujian Mutu DPUPR Prov. Kal-Teng.

Pada pelaksanaan dilapangan ditekankan pada setiap memulai pekerjaan pengecoran kontraktor harus melakukan pengujian atas beton yang akan dipakai, diantaranya :

\section{Uji Kuat Tekan Beton}

Metoda ini dimaksudkan sebagai pegangan dalam pengujian ini untuk menentukan kuat tekan (compressive strength) beton dengan benda $u j$ berbentuk silinder yang dibuat dan dimatangkan (curring) di lapangan.

Pengujian ini dilakukan terhadap beton segar (fresh concrete) yang mewakili campuran beton, bentuk benda uji yang dipakai yaitu silinder; hasil pengujian ini digunakan dalam pekerjaan :

a. Perencanaan campuran beton;

b. Pengendalian mutu beton pada pelaksanaan pembetonan.

Uji kuat tekan beton mengacu pada $P B I 1971$ N.I.-2 dan SNI 03-2847-2002.

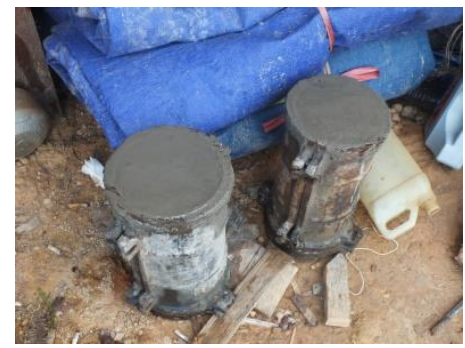

Gambar 3. Alat Silinder Uji Kuat Tekan Beton

\section{Concrete Slump Test}

Slump pada dasarnya merupakan salah satu pengetesan sederhana untuk mengetahui workability beton segar sebelum diterima dan diaplikasikan dalam pekerjaan pengecoran.

Workability beton segar pada umumnya diasosiasikan dengan :

a. Homogenitas atau kerataan campuran adukan beton segar (homogenity)

b. Kelekatan adukan pasta semen (cohesiveness)

c. Kemampuan alir beton segar (flowability)

d. Kemampuan beton segar mempertahankan kerataan dan kelekatan jika dipindah dengan alat angkut (mobility)

e. Mengindikasikan apakah beton segar masih dalam kondisi plastis (plasticity).

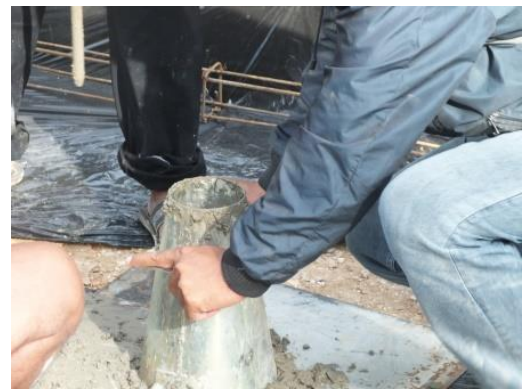

Gambar 4. Alat Kubus Slump Beton

Uji Slump mengacu pada SNI 1972-2008 dan ICS 91.100.30.

\section{Metode Sambungan}

Sambungan pada perkerasan beton semen bertujuan untuk :

a. Membatasi tegangan dan pengendalian retak yang disebabkan oleh penyusutan dan beban lalu-lintas.

b. Memudahkan pelaksanaan.

c. Mengakomodasi gerakan pelat akibat beban dinamis kendaraan.

Metode sambungan jalan perkerasan beton ada 3 (tiga) jenis antara lain :

1. Sambungan memanjang.

2. Sambungan susut melintang.

3. Sambungan isolasi.

Untuk proyek Peningkatan Jalan Posing dipakai sambungan memanjang dengan Batang Pengikat (Tie Bars) Pemasangan sambungan memanjang diperlukan untuk mengendalikan terjadinya retak memanjang. Jarak antar sambungan 4.50 meter dan dilengkapi dengan batang ulir dengan mutu minimum BJTU- 24 diameter $12 \mathrm{~mm}$ dan diameter $22 \mathrm{~mm}$. Jarak antar batang pengikat yang digunakan adalah $30 \mathrm{~cm}$.

\section{Aplikasi Pelaksanaan Jalan Beton}

\section{A. Pembentukan Badan Jalan}

Untuk membentuk badan jalan digunakan material Timbunan Pilihan, yaitu bahan tanah berpasir yang di blending menggunakan Excavator. Alat yang dibutuhkan untuk pekerjaan ini adalah :

- Motor Grider

- Vibrator Roller
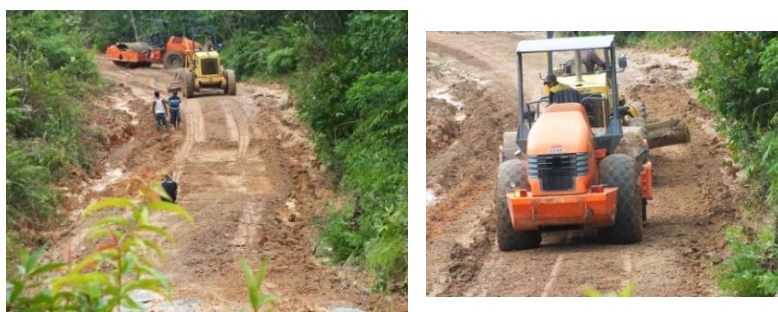
Gambar 5. Proses Pemadatan lapisan bawah (Sub Base Course) Pembentukan badan jalan dengan Timbunan Pilihan.

\section{B. Pekerjaan Perkerasan Beton}

Beberapa yang harus dipersiapkan sebelum memulai pekerjaan beton diantaranya persiapan lokasi pekerjaan, penghamparan plastik beton, acuan dan rel sisi, perletakan tulangan baja. Alat yang dibutuhkan adalah :

- Truck Mixer

- Excavator

- Water Pump
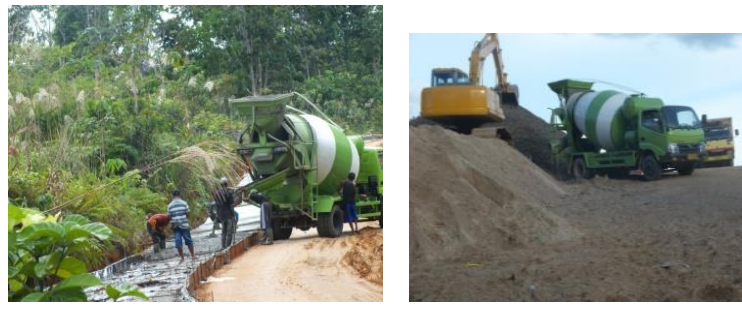

Gambar 6.. Proses Penghamparan Perkerasan Beton. Pengadukan beton dengan Truck Mixer

\section{Pekerjaan Mobilisasi}

Dalam setiap pelaksanaan proyek mobilisasi pekerjaan pertama kali dilakukan ada beberapa hal yang harus dipersiapkan yaitu :

- Lokasi untuk Base Camp

- Manajemen dan Keselamatan Lalu Lintas

- Penyiapan Laboraturium Lapangan

- Sistem Pengendalian Mutu

- Analisis Dampak Lingkungan

Jalan Posing adalah jalan arteri kabupaten satusatunya yang menghubungkan ibu kota kabupaten ke tiga kecamatan disamping itu juga sebagai jalan alternatif menuju ibu kota Provinsi. Masalah infrastruktur jalan menjadi prioritas utama pembangunan di Kabupaten Murung Raya mengingat sebelum di bangun jalan Posing satu-satunya akses transportasi masyarakat hanya melewati sungai Barito jarak dan waktu tempunya cukup lama, Peningkatan Jalan Posing berdampak pada terbukanya peluang usaha baru, serta memacu pertumbuhan ekonomi dan peningkatan kualitas hidup masyarakat.
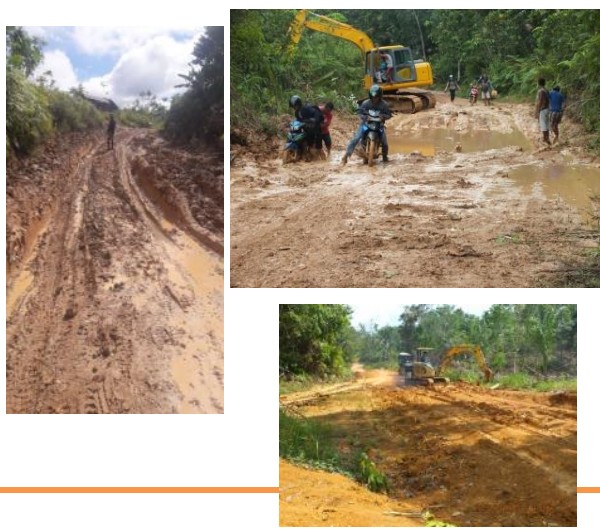

Gambar. Ruas Jalan Sebelum dihampar (Sub Base Course)
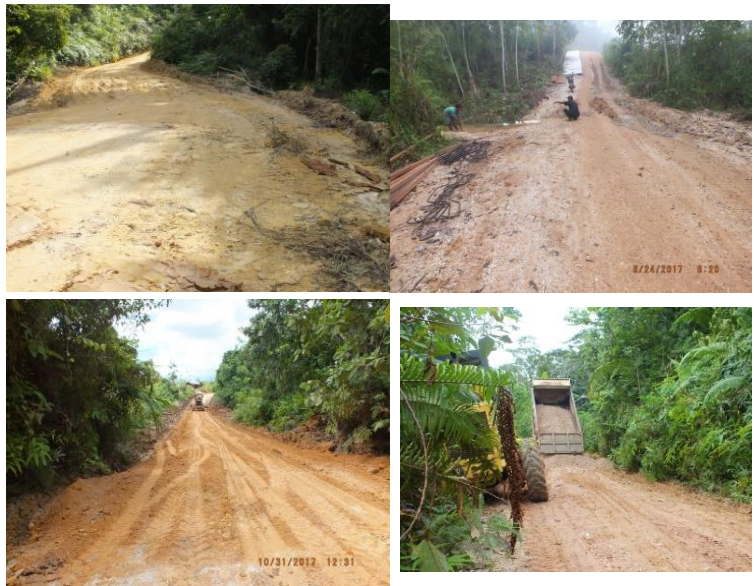

Gambar. Ruas Jalan sudah dihampar (Sub Base Course)
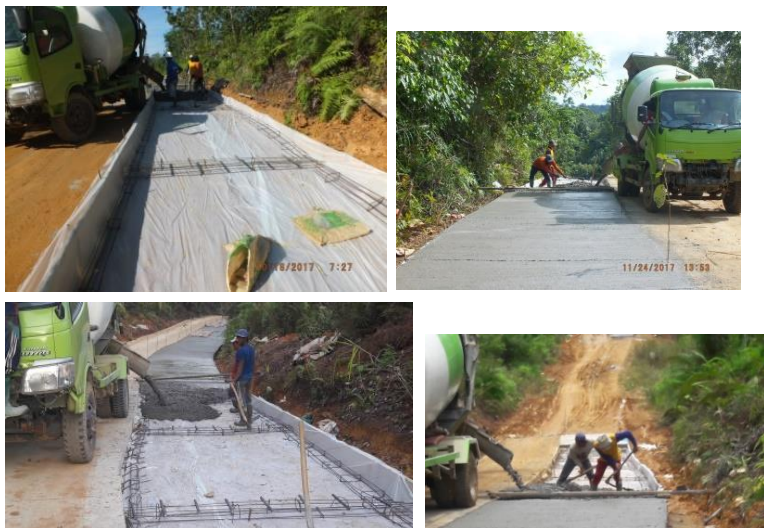

Gambar. Proses Pengecoran Beton $f^{\prime} 20$ MPa
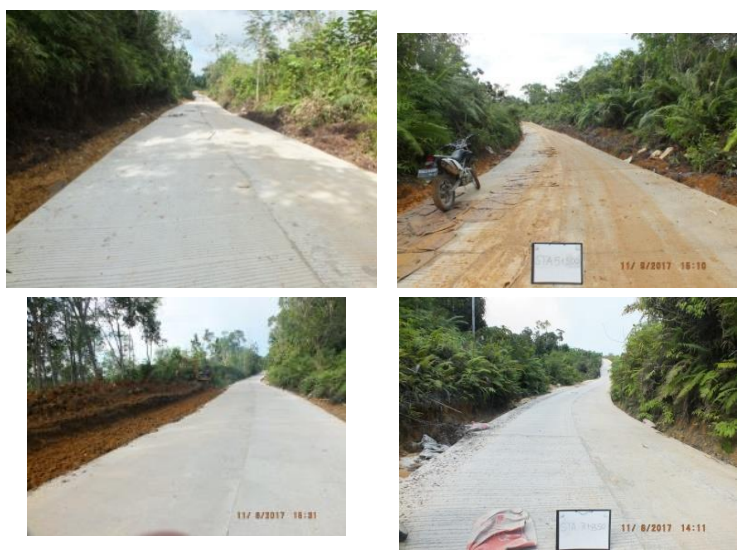

Gambar Ruas Jalan Perkerasan Beton (Rigid Pavement). 


\section{Kesimpulan}

Jalan adalah serangkaian simpul atau ruang kegiatan yang dihubungkan oleh ruang lalu lintas hingga membentuk satu kesatuan sistem jaringan untuk keperluan penyelenggaraan lalu lintas dan angkutan jalan.

\section{Saran}

Permukaan perkerasan jalan raya harus selalu dijaga dan dirawat agar tetap aman untuk dilalui bagi pengguna jalan.

\section{Ucapan Terima Kasih}

Ucapan terima kasih ini ditujukan kepada semua pihak yang telah memberi bantuan, dorongan, semangat serta bimbingan kepada penulis selama penyusunan bulletin ini sehingga dapat menyelesaikan Buletin ini. Dengan segala rasa kerendahan hati, penulis menyampaikan terimakasih yang sebesar-besarnya serta penghargaan yang setinggi-tingginya kepada yang terhormat :

- Ibu Ir. Iryanti Fatyasari N. ST, MT, Ph.D selaku Dosen Pembibing akademik saya.

- Bpk. Mohammad Rofiq, ST. selaku PPK Peningkatan Jalan Posing, Bidang Bina Marga Dinas PUPR Kab. Murung Raya.

- Bpk. AGUS SULISTYO Direktur PT. DRA KAMIL ARTA selaku Kontraktor Pelaksana.

- Semua pihak yang tidak bisa disebutkan satu-persatu yang telah membantu dalam pembuatan buletin ini. Semoga Tuhan membalas dengan pahala yang berlipat ganda. Amin.

\section{Referensi}

American Association of State Highway and Transportation Officials (AASHTO).

Arthur Wignall, 1999, Proyek Jalan : Teori dan Praktek, Penerbit Erlangga. Jakarta.

Perencanaan perkerasan jalan beton semen Pd T-142003. Departemen Permukiman dan Prasarana Wilayah.

Spesifikasi Teknis Perencanaan Peningkatan Jalan Posing. 